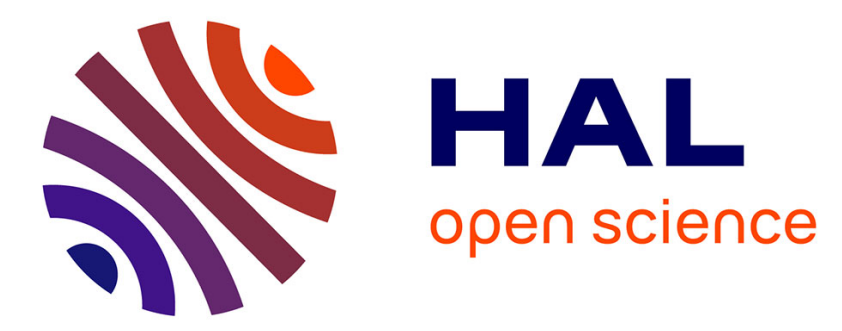

\title{
Vegetalized Complex Partition (VCP): Impact of a Green Roof under a Humid Tropical Climate, Comparison between Hong Kong and Reunion Island
}

Aurélien Jean, Teddy Jeannick Libelle, Frédéric Miranville, Mario Medina

\section{- To cite this version:}

Aurélien Jean, Teddy Jeannick Libelle, Frédéric Miranville, Mario Medina. Vegetalized Complex Partition (VCP): Impact of a Green Roof under a Humid Tropical Climate, Comparison between Hong Kong and Reunion Island. 2014, pp.273 - 277. 10.4028/www.scientific.net/AMM.705.273 . hal-01110507

\author{
HAL Id: hal-01110507 \\ https://hal.science/hal-01110507
}

Submitted on 11 Jul 2015

HAL is a multi-disciplinary open access archive for the deposit and dissemination of scientific research documents, whether they are published or not. The documents may come from teaching and research institutions in France or abroad, or from public or private research centers.
L'archive ouverte pluridisciplinaire $\mathbf{H A L}$, est destinée au dépôt et à la diffusion de documents scientifiques de niveau recherche, publiés ou non, émanant des établissements d'enseignement et de recherche français ou étrangers, des laboratoires publics ou privés. 


\title{
VEGETALIZED COMPLEX PARTITION (VCP): IMPACT OF A GREEN ROOF UNDER A HUMID TROPICAL CLIMATE, COMPARISON BETWEEN HONG KONG AND REUNION ISLAND.
}

\author{
Aurélien P. Jean ${ }^{1, a^{*}}$, Teddy Libelle ${ }^{1, b}$, Frédéric Miranville ${ }^{1, c}$, Mario A. Medina ${ }^{2, d}$ \\ ${ }^{1}$ Physics and Mathematical Engineering Laboratory for Energy and Environment, University of Reunion, France \\ ${ }^{2}$ Civil, Environmental and Architectural Engineering Department, The University of Kansas, USA \\ a aurelien.jean@univ-reunion.fr, ${ }^{b}$ teddy.libelle@univ-reunion.fr, ${ }^{c}$ frederic.miranville@univ-reunion.fr, ${ }^{d}$ mmedina@ku.edu
}

Keywords: Vegetalized complex partition; VCP; Green roof; Zosya tenuifolia; Thermal impact; Energy performance; Tropical environment.

\begin{abstract}
.
The aim of this paper is to present the experimental results of a specific vegetated complex partition (VCP) and discuss the conclusions found from an interesting study case in Hong Kong, especially the presence of a strong upward heat flux in winter.

The experimented VCP configuration have never been tested in Reunion Island. It is located on a small scale building with a sloped roof covered with steel foil and under a humid tropical climate.

From March to August, the extensive VCP reduced the global average heat flow by $91.61 \%$ and the ceiling temperature by $9.3^{\circ} \mathrm{C}$, with a maximum average reduction of $18.9^{\circ} \mathrm{C}$ at noon.

Compares to the results from Hong Kong, three of the four conclusions have been observed or deduced from the experimented VCP's results. The fourth conclusion (about heat flow loss in winter) have not been observed. But, based on the results, a precision of the explanation of its origin is proposed: the evaporation process act like an heat loss amplifier.
\end{abstract}

\section{Introduction}

Vegetalized complex partition (VCP), such as green roofs, are a very interesting research subject. Since the first published study, in 1977 [1], the specific knowledge of these specific partitions have been rising, but we are far from a full understanding of its thermal field evolution (spatially and temporally). In fact, a full understanding would be almost impossible considering the cross discipline aspect of this study field (thermal and mass transfer, biological and chemical process, etc.). But using some assumptions, we can simplify enough the subject to understand it, and to be able to predict its evolution. To achieve this goal, numerous of experiments were conducted in continental [2], temperate [3, 4] or Mediterranean [5, 6] climates. But only a very few have been done in a humid tropical climates [7,8]. However, one of these study showed very interesting results. In Hong Kong, the vegetalized complex partition (VCP) did act, as expected, as an isolation by summer but in winter it acts as a heat loss amplifier [9].

Considering these remarks, an experiment has been conducted under a humid tropical climate (Reunion Island). This one had two objectives: first to know the impact of a VCP on a building thermal field, and secondly to check if the specific winter heat loss depicted [9] can happen with an extensive VCP in Reunion Island.

\section{Experimental design and data acquisition}

As introduced, an experiment have been conducted under a humid tropical climate. By convenience, the VCP is installed on a small scale building (one third), called "Isotest". The Isotest have four walls filled with polyurethane ${ }^{1}$ creating a volume of $0.36 \mathrm{~m}^{3}$, which is hermetically sealed and fully validated by numerous previous experiments [10]. The roof of the Isotest structure have a

\footnotetext{
1 The walls are made of the partition used for the conception of cold chambers.
} 
slope of $27^{\circ}$ and is composed by $8 \mathrm{~mm}$ of plaster board, $116 \mathrm{~mm}$ of air and $1 \mathrm{~mm}$ of steel foil (fig. 1). This plain configuration is used as reference design. By opposition, the VCP design is composed by a plain Isotest on which substrate $(80 \mathrm{~mm})$ and vegetation $(40 \mathrm{~mm})$ are installed (fig. 1). The substrate is made of lava-rock (average diameter: $20 \mathrm{~mm}$ ) and organic amendment, respectively at $85 \%$ and $15 \%$. On the top of the substrate is situated the vegetation: "Zosya Tenuifolia". This kind of grass, naturally present in Reunion Island, have coverage rate of $\sim 100 \%$ and possess a temporal and spatial homogeneity (figure 1).

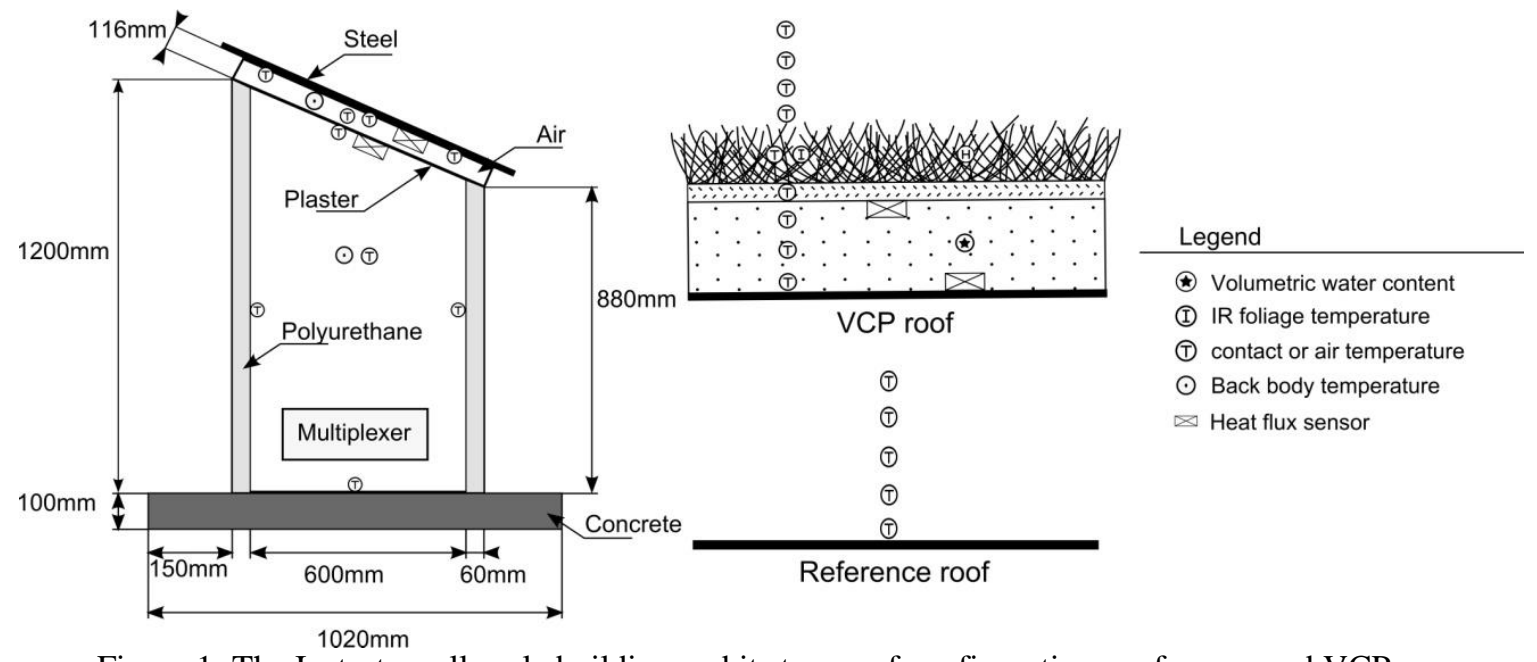

Figure 1: The Isotest small scale building and its two roof configurations: reference and VCP

About the sensors, contact and air temperatures are obtained by type $\mathrm{T}$ thermocouples, while grass foliage temperature is acquired by an infra-red thermometer. The heat flux is measured by a thermopile. Two types are used in function of the location: a thin one (Captec) is used under the steel foil of the roof, and considering the mechanic conditions, a protected one is placed into the substrate (HPF01). The volumetric water content is obtained by a reflectometric sensor (CS616). All of these probes are connected to a data logger (CR3000), directly or through a multiplexer (AM25T). Finally, a computer record automatically each sample under a ".csv" text file (figure 2).

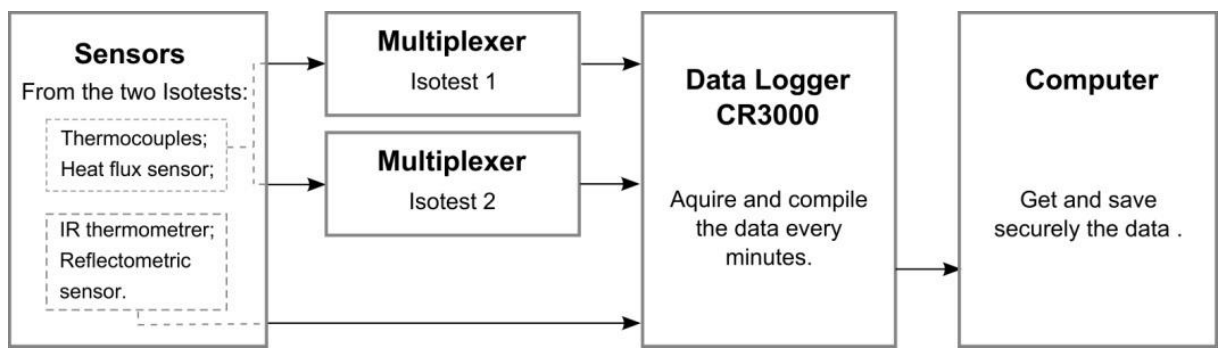

Figure 2: Synoptic of the data acquisition.

\section{Experimentation}

Localized in Saint-Pierre, French city of Reunion Island (situated in the Indian Ocean: $21^{\circ} 19^{\prime} \mathrm{S}$, $55^{\circ} 28^{\prime} \mathrm{E}$ ), the experimentation has been conducted from mid March to mid August 2014, so covering almost half of the summer and winter periods. Evolving during this period, the meteorological conditions are succinctly presented by the next paragraph.

The daily average temperature of ambient air is from $26.7^{\circ} \mathrm{C}$ to $21.2^{\circ} \mathrm{C}$ with a diurnal evolution of $8^{\circ} \mathrm{C}$. Unlike the air temperature, relative humidity's daily average is almost constant at $75 \%$ with a diurnal evolution of $30 \%$ within all the experimentation. The maximum solar irradiation (at noon) evolves from Mach to August respectively from $1000 \mathrm{~W} / \mathrm{m}^{2}$ to $600 \mathrm{~W} / \mathrm{m}^{2}$. And to finish, the wind speed at 2 meter evolves from $1.75 \mathrm{~m} / \mathrm{s}$ to $2.4 \mathrm{~m} / \mathrm{s}$ with some fluctuations $( \pm 1 \mathrm{~m} / \mathrm{s})$ and specific events (without seasonality). 


\section{Results and discussion}

According to the result, the VCP allows to reduce the heat flux through the steel foil. Compared to the reference roof, $94.61 \%$ of the heat gain into the building and $88.62 \%$ of the heat loss are erased. These percentages are very high and have to be used with precaution, especially the heat loss reduction. Indeed, in this context the reduction happens only because there is no heat to release, since the only heat production comes from the solar irradiation (there is no heat production inside the building). Moreover, considering the phenomena inside the VCP it is very hazardous to extrapolate this loss reduction to a case with heat production.

The modification of the heat flux impact also the temperatures (detailed into the table 1). For example, the most important modification is observed on the steel foil, who sees its temperature lowered by $20.3 \pm 11.0^{\circ} \mathrm{C}$, with a maximum reduction of $41.4^{\circ} \mathrm{C}$ at noon (which represent $\sim 57 \%$ ). Nota: because of the circadian seasonality the standard deviation is usually important. So, the most representative key parameter is the temperature difference at noon: $\Delta \mathrm{T}^{\mathrm{max}}$.

Table 1: Differences between the reference Isotest and the VCP Isotest (average from March to August)

\begin{tabular}{|c|c|c|c|c|c|c|c|c|}
\cline { 2 - 8 } \multicolumn{1}{c|}{} & \multicolumn{2}{c|}{ Heat Flux } & \multicolumn{2}{c|}{$\mathrm{T}_{\text {steel }}$} & \multicolumn{2}{c|}{$\mathrm{T}_{\text {air }}$} & \multicolumn{2}{c|}{$\mathrm{T}_{\text {plaster }}$} \\
\cline { 2 - 9 } & Gain & Loss & $\Delta \mathrm{T}$ & $\Delta \mathrm{T}^{\max }$ & $\Delta \mathrm{T}$ & $\Delta \mathrm{T}^{\max }$ & $\Delta \mathrm{T}$ & $\Delta \mathrm{T}^{\max }$ \\
\hline Average & $94.61 \%$ & $88.62 \%$ & $20.3 \pm 11.0^{\circ} \mathrm{C}$ & $41.4^{\circ} \mathrm{C}$ & $4.5 \pm 3.1^{\circ} \mathrm{C}$ & $10.3^{\circ} \mathrm{C}$ & $9.3 \pm 5.8^{\circ} \mathrm{C}$ & $18.9^{\circ} \mathrm{C}$ \\
\hline
\end{tabular}

Where $\Delta \mathrm{T}$ represent the average temperature difference between the two configurations. The temperature and heat flux measurement errors are respectively: $\pm 1^{\circ} \mathrm{C}$ and $\pm 6.4 \%$.

Considering this design, under these specific conditions, and by the hypothesis of quasi-static state, the experimented VCP can be globally approximated by a thermal resistance of $R_{\mathrm{vcp}}=0.302 \pm 0.016 \mathrm{~m}^{2} . \mathrm{K} \cdot \mathrm{W}^{-1}$. This resistance cover the vegetation and substrate layers, who respectively can be approximated by $R_{v e g}=0.051 \pm 0.003 \mathrm{~m}^{2} . \mathrm{K} \cdot \mathrm{W}^{-1}$ and $\mathrm{R}_{\mathrm{sub}}=0.250 \pm 0.013 \mathrm{~m}^{2} . \mathrm{K} \cdot \mathrm{W}^{-1}$. The dissociation of $R_{v c p}$ into $R_{\text {sub }}$ and $R_{v e g}$ lead to an intrinsic thermal property of these specific layers: their thermal conductivities. With a depth of $40 \mathrm{~mm}$ and $80 \mathrm{~mm}$, for the vegetation and the substrate, it appears: $\lambda_{\text {sub }}=0.319 \pm 0.017 \quad \mathrm{~W} . \mathrm{m}^{-1} \cdot \mathrm{K}^{-1}$ and $\lambda_{\text {veg }}=0.775 \pm 0.046 \quad \mathrm{~W} \cdot \mathrm{m}^{-1} \cdot \mathrm{K}^{-1}$ $\left(\lambda_{\mathrm{vcp}}=0.397 \pm 0.022 \mathrm{~W} \cdot \mathrm{m}^{-1} \cdot \mathrm{K}^{-1}\right)$.

From another point of view, the VCP impact can be characterized by the averaged heat flux density reduction between the reference and the VCP Isotests (loss and gain combined). With an averaged heat flux density reduction of $8.19 \pm 0.41 \mathrm{~W} \cdot \mathrm{m}^{-2}$, the tested design allows an energy ${ }^{2}$ consumption economy of $30.0 \pm 1.5 \mathrm{kWhe} / \mathrm{m}^{2}$ over the five months of the experiment.

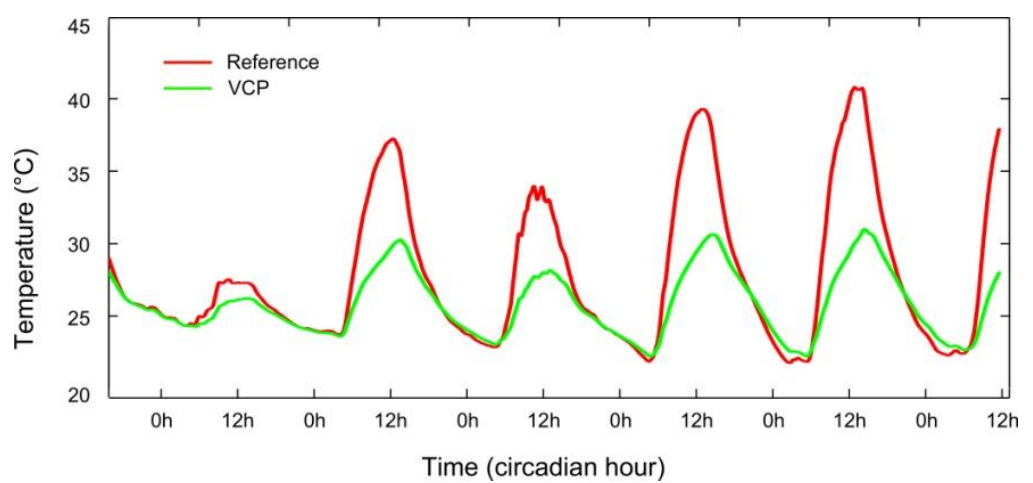

Figure 3: Evolution of the reference and VCP Isotests air temperature from the $23^{\text {rd }}$ to the $28^{\text {th }}$ of March 2014.

About the origin of these results, since the only present heat source is the solar irradiation, the main factor seems to be the radiative protection created by the VCP. But, this is not the only phenomenon who is able to lead to a heat gain reduction. Indeed, the inertia of the system possess the capacity of delaying the heat flux and lowering its intensity (both visible in figure 3 ). A third phenomenon is the vaporization of the water, by evaporation into the substrate or by plant's transpiration. But the substrate have a very little water retention capacity over few days, explaining

2 In this case the hypothesis of a performance coefficient of 1 is made, so one thermal $\mathrm{kWh}$ equal one electric $\mathrm{kWh}$. 
the very low volumetric water content. So the thermal impact mainly comes from the inertia and the radiative protection.

To finish, a particularity of these results is the low seasonality variation. This behavior is explained by the low variation of the climatic conditions, coupled with an absence of inside heating source and most of all a very low volumetric water content.

\section{Comparison between results in Hong Kong and in Reunion Island}

Based on Jim and Tsang experiment [9], the goal of this section is to highlight the similarities and differences between their conclusions and the results presented previously.

The Jim and Tsang's experimental design describes a sky woodland over $150 \mathrm{~m}^{2}$, involving a 100 $\mathrm{cm}$ thick layer of soil, composed of $80 \mathrm{~cm}$ subsoil and $20 \mathrm{~cm}$ topsoil enriched with mature compost. The trees have a final height of 5-10 m. So, except for the similar climate (humid tropical), this experimental design is very different from the one presented in this paper. Nota: these differences impact the observed phenomena only by modulation of their intensities, which explain the obtained similarities. Below is synthesized the four remarks (in italic) of Jim and Tsang, followed by our results, conclusion and/or propositions.

1) "The transpiration rate varies widely depending on seasonal and weather conditions"

The transpiration rate have not been measured, but considering the very low volumetric water content of the substrate, and its evolution, the vegetation layer do absorb a large amount of stored water. Furthermore, this substrate water content reduction is strongly linked to the solar radiation. So, the vegetation being healthy, the evapotranspiration rate (these two phenomena cannot be dissociated here) varies widely depending on seasonal and weather conditions.

2) "The tree canopy layer could reduce solar radiation reaching the soil surface"

At mid-day, the average temperature reduction between the top of the substrate and vegetation layers is about $47 \pm 5 \%$. Since the transpiration rate is low (because of the low volumetric water content), most of the impact comes from the reduction of the solar radiation reaching the soil surface. So the canopy do act as a radiative shield.

3) "The soil substrate layer of the intensive green roof can be considered as a large heat sink on the rooftop to reduce temperature fluctuation"

The experimented VCP is extensive, but even with $80 \mathrm{~mm}$ of lava-rock the inertia's impact can be observed, delaying the heat flux and lowering its intensity (fig. 3). So, a substrate layer can be considered as a large heat sink to reduce temperature fluctuation.

4) "In winter, the subtropical intensive green roof triggers notable upward heat flow from the substrate to the ambient air"

This "notable upward heat flow" have not been observed during the experiment. This difference allows to investigate (by comparison) the origin of this peculiar phenomenon. According to Jim and Tsang, the upward heat flow comes from the negative temperature difference between the substrate and the inside air temperature, which induces some sensible and latent thermal transfers.

Considering these conclusions and our results, the origin of the temperature difference (so the upward flow) can be explained by two set of parameters: the VCP design and the meteorological conditions. Indeed, the VCP design's choice defines its thermal characteristics and phenomena intensities (ex: the water retention capacity influence the evaporation phenomenon, etc.). Among these phenomena, evaporation is able to impact (lower) the thermal filed into the VCP, even with low solar radiation (or by nigth). But, as long as there is no hydric stress, it is essentially governed by the air relative humidity and wind speed.

So, the upward heat flow in winter could comes from a high substrate water content, acting as heat loss amplifier through evaporation process if associated with the adequate relative humidity and wind speed.

Nota: several combinations of meteorological conditions can lead to the same evaporation rate. 


\section{Conclusions}

This paper presents, in a first place, the results and discussions about an experimented vegetated complex partition (VCP) on small scale building and under a humid tropical climate. Then a comparison is made with the conclusions of a study made in Hong Kong.

Over five months (March to August), the extensive VCP shows some very interesting heat flow reduction compared to the reference building (global average of 91.61\%). This lead to reduce the ceiling temperature by $9.3 \pm 5.8^{\circ} \mathrm{C}$, with a maximum average reduction at noon of $18.9^{\circ} \mathrm{C}$. The data manipulation allows to get the VCP resistance $R_{v c p}=0.302 \pm 0.016 \mathrm{~m}^{2} . \mathrm{K} . \mathrm{W}^{-1}$, then the substrate (lavarock) and vegetation (Zosya Tenuifolia) layer conductivities: $\lambda_{\text {sub }}=0.319 \pm 0.017 \mathrm{~W} \cdot \mathrm{m}^{-1} \cdot \mathrm{K}^{-1}$ and $\lambda_{\text {veg }}=$ $0.775 \pm 0.046 \mathrm{~W} \cdot \mathrm{m}^{-1} \cdot \mathrm{K}^{-1}$. Globally, the VCP induces a reduction of $8.19 \pm 0.41 \mathrm{~W} \cdot \mathrm{m}^{-2}$, which allows an energy consumption economy of $30.0 \pm 1.5 \mathrm{kWhe} / \mathrm{m}^{2}$. So, this solution is thermally efficient.

Compares to the results from the Hong Kong's study, similar conclusions or deductions are made about three aspects including: the seasonal and weather conditions impact on the transpiration rate; the canopy layer radiative shield property; and the substrate layer inertia. The fourth conclusion focused on a winter upward heat flow from the substrate to the ambient air. This phenomenon has not been observed, but a comparative study of the set-up allowed to propose a precision about its origin. This upward heat flow seems to be governed by the meteorological conditions and VCP water content, the evaporation process acting like an heat loss amplifier.

\section{References}

[1] Hoeschele, K. and Schmidt, H. Klimatische wirkung elner dachbegrunung. Garten u Landschaft, 87 (1977) 334-337.

[2] Alar Teemusk, Ülo Mander, "Temperature regime of planted roofs compared with conventional roofing systems", Ecological Engineering, 36 (2010) 91-95.

[3] Liesecke, H.-J., Krupka, B., and Brueggemann, H. "Ausfuhrung und unterhaltung von extensivbegruenungen und einfachen intensivbegruenungen." In Grundlagen der Dachbegruenung Zur Planung, page 18, Patzer Berlag, Berlin - Hannover, 1989.

[4] Renato M. Lazzarin, Francesco Castellotti, Filippo Busato, "Experimental measurements and numerical modelling of a green roof", Energy and Buildings, 37 (2005) 1260-1267

[5] R. Fioretti, A. Palla, L.G. Lanza, P. Principi, "Green roof energy and water related performance in the Mediterranean climate", Building and Environment, 45 (2010) 1890-1904

[6] Eumorfopoulou E, Aravantinos D., "The contribution of a planted roof to the thermal protection of buildings in Greece". Energy and Buildings, 27 (1998) 29-36.

[7] Wong NH, Tay SF, Wong R, Ong CL, Sia A. "Life cycle cost analysis of rooftop gardens in Singapore." Building and Environment, 38 (2003) 499-509

[8] C.Y. Jim and Hongming He, "Coupling heat flux dynamics with meteorological conditions in the green roof ecosystem", Ecological Engineering, 36 (2010) 1052-1063.

[9] C.Y. Jim and S.W. Tsang, "Biophysical properties and thermal performance of an intensive green roof", Building and Environment, 46 (2011) 1263-1274.

[10] Bigot, D., Miranville, F., Fakra, A., and Boyer, H. A nodal thermal model for photovoltaic, systems : Impact on building temperature fields and elements of validation for tropical and humid climatic conditions. Energy and Buildings, 41(9):1117-1126, 2009. 